\title{
Recent changes in the patterns of chronic digestive disease in the United Kingdom
}

\author{
M. J. S. LANGMAN \\ M.D., F.R.C.P. \\ Department of Therapeutics, University Hospital, Nottingham NG7 2UH
}

Chronic alimentary complaints, though persistent in individuals, impose a varying degree of burden upon society in general. The reasons for these fluctuations remain largely unknown, but the speed with which changes occur suggests that the impact of environmental factors can become apparent after relatively short intervals have passed in which those influences have been at work.

These concepts can be illustrated by considering peptic ulcer, coeliac disease and chronic inflammatory bowel disease.

\section{Peptic ulcer}

The abrupt changes in patterns of ulcer frequency which occurred at the end of the nineteenth century with the decline in frequency of gastric ulcer in younger women and the rise to prominence of duodenal ulcer in younger and middle-aged men has been well described. These alterations seem to have occurred rapidly, are unlikely to be accounted for by systematic errors in methods of ascertainment, and probably occurred in much of Europe and the U.S.A. at the same time. We cannot, however, even guess at the causes, although clear evidence of occupational factors was produced by Avery Jones and Doll over thirty years ago (Doll and Avery Jones, 1951).

Duodenal ulceration probably reached a peak frequency some 20 years ago, and has since declined. Exact measurement of frequency rates is difficult. Comparative diagnostic figures for differing time periods are not available, and even if they were, would be uninterpretable because of the shift of diagnostic emphasis from radiology to endoscopy. At the other end of the scale, mortality rates are of doubtful value. Few younger ulcer patients die of their disease, and if they do it is likely to be because they have suffered from unfortunate sequelae to complicated disease, whilst deaths in older people might more properly be ascribed to the associated diseases, usually cardio-pulmonary, which made ulcer treatment more difficult.

Overall hospital admission rates are of limited value. If patients are admitted then this reflects a combination of actual physical need and the physician's or surgeon's perception of that need.

The pattern of overall duodenal ulcer admissions as measured by hospital discharge and death rates in England and Wales from 1958 to 1977 altered considerably although for much of that time rates do not seem to have varied, but in the later years fell sharply (Coggon et al., 1981). At least part of this late change seems likely to have been due to altered management policies, with a great emphasis on outpatient treatment. This view can be supported by considering trends during the same period in ulcer perforation rates in men, which fell steadily throughout the time period (Fig. 1). If we assume that the ratio of perforated to non-perforated ulcer remained constant, then a relatively greater fall in overall admissions compared with admissions with perforation would suggest a change in management policy, though it is noteworthy that the steep fall antedates the introduction of $\mathrm{H}_{2}$ antagonist treatment.

The numbers of people admitted with gastric ulcer of all clinical types also fell, but as with duodenal ulcer the main changes occurred in men. This is brought out by perforation rates which, taken overall, changed little in women, whilst those in men approximately halved. A complete picture cannot, however, be obtained without examining variations by age, and, as in earlier periods, marked differences can be seen. Taken overall, rates of admission for perforated disease have fallen markedly, and precipitously in younger women with perforated gastric ulcer, whilst perforated duodenal ulcer seems to have become more common in older women (Table 1).

Such differential changes should have aetiological morals. They cannot simply be ascribed to the general play of environmental influences, and it seems more likely that younger individuals are either less likely to be exposed to, or more likely to be resistant to, predisposing factors, whilst the reverse is true in older women. What these influences are remains unclear, but they may differ. Thus it is possible that the increased perforation rate in older women reflects general exposure to treatment with 


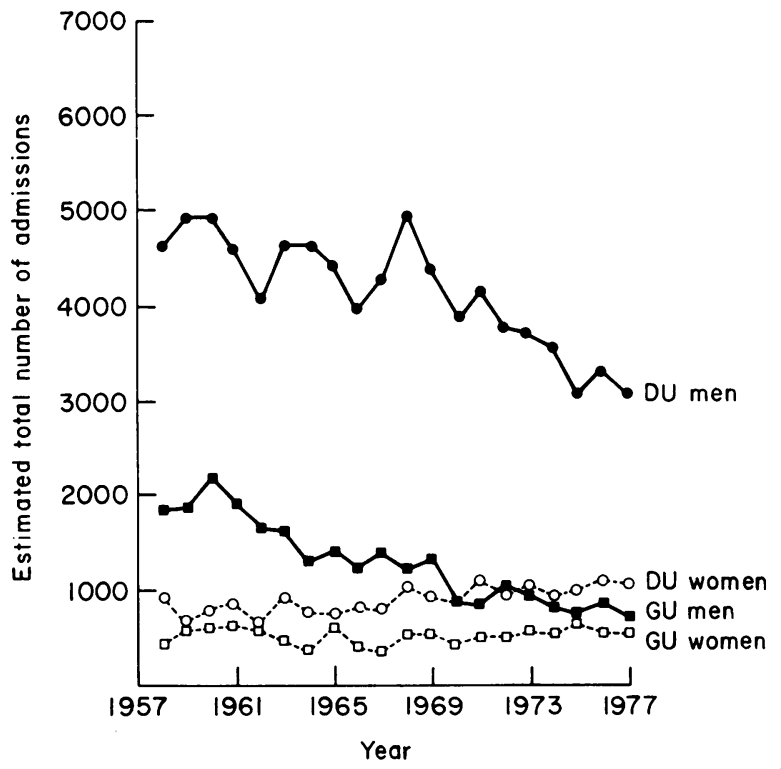

FIG. 1. Estimated total numbers of admissions with perforated ülcer in England and Wales, 1958-77 (from Coggon, Lambert and Langman, 1981 by kind permission of the Editor of the Lancet). $\mathrm{GU}=$ gastric ulcer, $\mathrm{DU}=$ duodenal ulcer.

TABLE 1. Admissions for perforated ulcer in England and Wales, 1958-77 as 5-year average rates per 100,000 per annum

\begin{tabular}{lcccc}
\hline & \multicolumn{4}{c}{ Age (years) } \\
\cline { 2 - 5 } & 25 & 35 & 65 & $75+$ \\
\hline Gastric ulcer: men & & & & \\
$\quad$ 1958-62 & $5 \cdot 0$ & $9 \cdot 7$ & $21 \cdot 6$ & $29 \cdot 5$ \\
1973-77 & $0 \cdot 7$ & $2 \cdot 3$ & $10 \cdot 1$ & $20 \cdot 5$ \\
\% change & -86 & -76 & -53 & -31 \\
& & & & \\
Gastric ulcer: women & & & & \\
1958-62 & $0 \cdot 8$ & $1 \cdot 5$ & $7 \cdot 0$ & $10 \cdot 7$ \\
1973-77 & $0 \cdot 3$ & $1 \cdot 2$ & $6 \cdot 2$ & $12 \cdot 0$ \\
\% change & -62 & -20 & -11 & +12 \\
& & & & \\
Duodenal ulcer: men & & & & \\
1958-62 & $19 \cdot 4$ & $27 \cdot 3$ & $44 \cdot 6$ & $45 \cdot 3$ \\
1973-77 & $10 \cdot 1$ & $16 \cdot 1$ & $33 \cdot 6$ & $45 \cdot 9$ \\
\% change & -48 & -41 & -25 & +1 \\
& & & & \\
Duodenal ulcer: women & & & & \\
1958-62 & $2 \cdot 7$ & 3.9 & $6 \cdot 8$ & $10 \cdot 8$ \\
1973-77 & $0 \cdot 8$ & $3 \cdot 5$ & $9 \cdot 9$ & $17 \cdot 3$ \\
\% change & -70 & -10 & +46 & +60 \\
\hline
\end{tabular}

non-steroidal anti-inflammatory drugs, although we must remember that the widespread clinical belief that non-steroidal anti-inflammatory drug treatment precipitates ulcer disease needs better support.
TABLE 2. Numbers and percentages of Coeliac Society Members from eight districts in England according to age and year of diagnosis (Langman et al., 1984)

\begin{tabular}{rcrrrrr}
\hline & \multicolumn{2}{c}{$0-9$ yrs } & \multicolumn{2}{c}{$10-24$ yrs } & \multicolumn{2}{c}{$25+$ yrs } \\
& No. & $\%$ & No. & $\%$ & No. & $\%$ \\
\hline $1968-69$ & 38 & $56 \cdot 7$ & 5 & $7 \cdot 5$ & 24 & $35 \cdot 8$ \\
$1970-71$ & 42 & $44 \cdot 2$ & 11 & $11 \cdot 6$ & 42 & $44 \cdot 2$ \\
$1972-73$ & 78 & $40 \cdot 7$ & 20 & $10 \cdot 4$ & 94 & $49 \cdot 0$ \\
$1974-75$ & 89 & $35 \cdot 1$ & 36 & $14 \cdot 2$ & 129 & $50 \cdot 8$ \\
$1976-77$ & 99 & $31 \cdot 3$ & 44 & $13 \cdot 9$ & 173 & $54 \cdot 8$ \\
$1978-79$ & 62 & $21 \cdot 7$ & 43 & $15 \cdot 1$ & 180 & $63 \cdot 2$ \\
$1980-81$ & 45 & $18 \cdot 7$ & 30 & $12 \cdot 4$ & 166 & 68.9 \\
\hline
\end{tabular}

\section{Coeliac disease}

The evidence of gluten sensitivity with lymphocyte and plasma cell infiltration of the flattened uppersmall bowel mucosa together with familial disease $\stackrel{\odot}{\circ}$ patterns and association with specific HLA groupshas tended to lead clinicians and epidemiologists tow neglect the significance of external environmentalo factors. In addition, as per-oral jejunal biopsy hasbeen applied with increasing freedom, and the $Z$ spectrum of coeliac disease has been generally recognized to include lesser degrees of nutritional or 3 haematological abnormality as well as classical patterns of steatorrhoea and general ill-health, these has been difficulty in deciding just how prevalent the complaint might be. New sets of data have progreș-:sively shown higher prevalence rates with figures $\bar{\sigma} \mathrm{f}$ one in a thousand or more now being the bench mark. These features, and the general lack of evidence of great variation in disease frequency in wheat-eating communities has lead interest to con- $\mathbb{D}$ centrate upon immunological features. However, it $\vec{F}$ has been suggested that coeliac disease is now being diagnosed very infrequently in infants in the United $\bar{T}$ Kingdom (Challacombe and Bayliss, 1980; Littlewood, Crollick and Richards, 1980; Dossetor, Gibson and McNeish, 1979). Reliable figures are hard to 3 collect: if specialist centres are seeing less patients then this may reflect a tendency for more diagnoses 3 . to be made by general paediatricians and physicians.

Nevertheless, several sets of data suggest that paediatric diagnoses have diminished sharply in numbers in the last few years, and we have observed a parallel fall in the numbers of early childhood o Coeliac Society members (Langman et al., 1984) (Table 2). This change, if real, has coincided with the $\sigma$ replacement of wheat-based with rice-based products $N$ as infant foods, but cause and effect remain to beN determined.

\section{Chronic inflammatory bowel disease}

There are now multiple sets of data which show? that the frequency of Crohn's disease has risen 
steadily in the last 20 years (Fig. 2). Precise quantitation is hampered by two major factors. Firstly, the increasing sophistication and general application of diagnostic techniques has inevitably meant that more diagnoses would be likely to be made, even if disease frequency were truly unchanged. Secondly, gastroenterologists have generally accepted that disease may not be confined to the small bowel, and can occur, often exclusively, in the large intestine. Consequently there is a chance that disease formerly grouped as ulcerative colitis would now be considered to be Crohn's disease.

Nevertheless, the steady upward trend which has been observed consistently in England, Wales and Scotland and Scandinavia, and which has not been matched by a fall in diagnoses or admissions with ulcerative colitis, is almost certainly real, at least in great part. It has been suggested that disease frequency may have stabilized or fallen recently, but it is too soon to be sure that any change does not represent an end to a trend to increased case finding, as sophisticated technical aids achieve their maximum potential.

Chronological trends in the incidence of ulcerative colitis are less well defined. Most series of data reviewing time trends have depended upon analyses of admission rates, and those which have included inpatient as well as out-patient attendances have tended to cover relatively short time periods. Nevertheless, the general picture suggests that disease incidence is fairly stable both from place to place in Western Europe and from time to time.

The causes of the changes in frequency of Crohn's disease are not understood, basically because we have little or no understanding of underlying environmental influences. A contrast has been drawn between the inverse correlation between disease frequency and the prevalence of infectious dysenter- ies, but whether such correlation is real, and reflects, for example, an abnormal reaction to infectious disease acquired late or a response to a pathogen, as yet unidentified, which flourishes when ordinary pathogens are few in number, or whether the correlation is false, is unclear.

TABLE 3. Smoking habit in patients with ulcerative colitis and Crohn's disease at symptom onset, compared with those of matched community controls (Logan et al., 1983a,b)

\begin{tabular}{|c|c|c|c|c|}
\hline & & $\begin{array}{l}\text { At symptom } \\
\text { onset } \\
(\%)\end{array}$ & $\begin{array}{c}\text { No. } \\
\text { studied }\end{array}$ & $\begin{array}{c}\text { Relative } \\
\text { risk* }\end{array}$ \\
\hline Ulcerative colitis & Non-smokers & 86 & 42 & \multirow{2}{*}{$6.0 P<0.001$} \\
\hline Controls & Non-smokers & 49 & 70 & \\
\hline Crohn's disease & Smokers & 70 & 42 & \multirow{2}{*}{$4.8 P<0.001$} \\
\hline Controls & Smokers & 31 & 119 & \\
\hline
\end{tabular}

* Computed from an enlarged data set for non-smokers and colitis and for smokers and Crohn's disease.

The hypothesis that liability to chronic inflammatory bowel disease represents a response to infection perhaps in the presence of predisposing dietary influences is ill-supported. Searches for specific pathogens have yielded conflicting results and no consistent body of data exists to support the belief that a virus, bacterium, or variant such as a cell-walldeficient organism is responsible for the disease.

Retrospective dietary analyses comparing patients with Crohn's disease and control individuals have consistently shown that patients have tended to have higher sugar intakes than the controls (Martini and Brandes, 1976; Thornton, Emmett and Heaton, 1979). Whether dietary histories can be used convin-

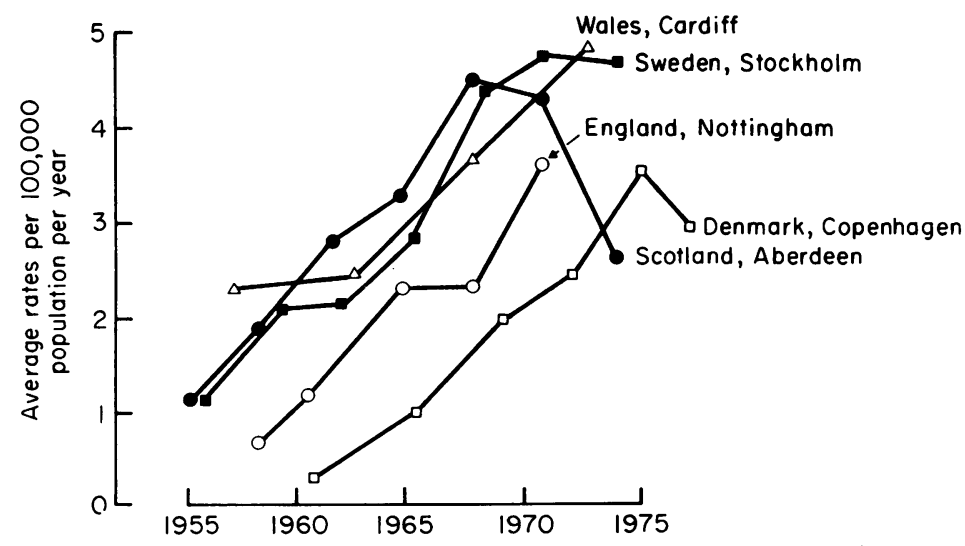

FIG. 2. The changing incidence of Crohn's disease (Logan and Langman, 1984 by kind permission of Oxford University Press); data taken from Binder et al., 1982; Hellers, 1981; Kyle and Stark, 1981; Mayberry, Rhodes and Hughes, 1979; Miller, Keighley and Langman, 1974. 
cingly to assess premorbid habits must be doubtful, but the available data suggest that the Crohn's disease patients did have higher sugar intakes before disease developed, and that decreased taste sensitivity to sugar does not explain the findings.

The largest difference so far detected between patients with inflammatory bowel disease and control groups has, surprisingly, been in smoking habits. The observation that ulcerative colitis patients are seldom smokers (Harries, Baird and Rhodes, 1982) has now been confirmed independently (Jick and Walker, 1983; Logan, Edmond and Langman, 1983a). The easy assumption would be that smokers tend to become non-smokers after disease diagnosis, but this does not seem to be true. We have found that the excess of non-smokers amongst colitics is largely accounted for by individuals who gave up smoking shortly before disease onset. The relative risk associated with non-smoking is high, a sixfold difference, compared with control individuals, and raises the possibility that factors closely related to smoking, or which are determined by smoking habits, determine disease liability. Further data obtained comparing smoking habits in community controls and Crohn's disease patients suggest that smoking is associated with liability to Crohn's disease, which raises the speculation that smoking habits in some way determine the site of inflammatory bowel disease in those who are going to develop it (Table 3). If these results are confirmed then it would suggest that close examination of the effects of smoking upon bowel habit and flora and upon intestinal motility and immune responses could be a fruitful method of seeking insight into causal mechanisms.

\section{Conclusion}

A major contribution of epidemiology to the study of the causes of chronic digestive disease has been to emphasize that patterns of illness can change rapidly in the community, suggesting that the predisposing influences may not necessarily have been of long standing. We are also beginning to obtain evidence of substantial differences in patterns of disease liability which should improve greatly the prospects of identifying specific risk factors.

\section{References}

Binder, V., Both, H., Hansen, P.K., Hendriksen, C., KReiner, S. \& TORP-PEDERSON, K. (1982) Incidence and prevalence of ulcerative colitis and Crohn's disease in the County of Copen hagen, 1962 to 1978. Gastroenterology, 83, 563.

Challacombe, D.N., \& BaYliss, J.M. (1980) Childhood coelia disease is disappearing. Lancet, i, 1360.

Coggon, D., LAMBERT, P. \& LANGMAN, M.J.S. (1981) 20 years of hospital admissions for peptic ulcer in England and Wales@ Lancet, i, 1302.

DOLL, R. \& AVERY JONES, F. (1951) Occupational factors in the aetiology of gastric and duodenal ulcers with an estimate of theip incidence in the general population. Medical Research Councit Special Report Series, No. 276. HMSO, London.

Dossetor, F.J.B., Gibson, M.M. \& MCNeish, A.S. (1979) Is the incidence of childhood coeliac disease changing? Archives Disease in Childhood, 54, 977.

Harries, A.D., Baird, A. \& Rhodes, J. (1982) Non-smoking. A feature of ulcerative colitis. British Medical Journal, 284, 706.

HELlers, G. (1981) Some epidemiological aspects of Crohn' disease in Stockholm County, 1955-1979, in: Recent Advances in Crohn's Disease (A. S. Pena, I. T. Weterman, C. C. Booth, W Strober, Eds.). p. 158. Martinus Nijhoff, The Hague.

JICK, H. \& WALKER, A.M. (1983) Cigarette smoking and ulcerativeo colitis. New England Journal of Medicine, 308, 261.

KYLE, J. \& STARK, J. (1980) Fall in the incidence of Crohn's disease $\vec{Z}$ Gut, 21, 340.

Langman, M.J.S., McConnell, T.H., Spiegelhalter, D.J. \&市 MCCONNELL, R.B. (1984) Changing patterns of coeliac disease 3 frequency: an analysis of Coeliac Society Membership Records Gut, in press

LiTTlewood, J.M., Crollick, A.J. \& RichaRds, I.D.G. (1989) Childhood coeliac disease is disappearing. Lancet, ii, 1359.

LogAN, R., EDMOND, M. \& LANGMAN, M.J.S. (1983a) Is n smoking associated with ulcerative colitis? Gut, 24, A499.

LogAN, R. \& LANGMAN, M.J.S. (1984) Gastrointestinal disease, in Oxford Textbook of Public Health (W. W. Holland, R. Detels, E. G. Knox, eds) Oxford University Press; in press.

Logan, R., Somerville, K.W., Edmond, M. \& LANGman, M.J.S.ํำ (1983b) Is cigarette smoking associated with Crohn's disease? Gut: 24, A980.

MARTINI, G.A. \& BRANDES, J.W. (1976) Increased consumption of refined carbohydrates in patients with Crohn's disease. Klinische Wochenschrift, 54, 367.

MAYBERRY, J., RHODES, J. \& HUGHES, L.E. (1979) Incidence of Crohn's disease in Cardiff between 1936 and 1977. Gut, 20, 602.

MilleR, D.S., Keighley, A.C. \& LaNGman, M.J.S. (1974) Changing patterns in epidemiology of Crohn's disease. Lancet, ii, 691.

Thornton, J.R., Emmett, P.M. \& Heaton, K.W. (1979) Diet and Crohn's disease: characteristics of the pre-illness diet. British Medical Journal, 2, 762. 